\title{
The FAB classification for acute myeloid leukaemia-is it outdated?
}

\author{
Christine M. Segeren ${ }^{*}$, Mars B. van 't Veer \\ Department of Haematology, Dr. Daniel den Hoed Cancer Centre, Groene Hilledijk 301, 3075 EA Rotterdam, Netherlands
}

Received 12 January 1996; revised 4 April 1996; accepted 9 April 1996

Keywords: Acute myeloid leukaemia; FAB classification; Immunophenotyping; Cytogenetics

\section{Introduction}

The purpose of a classification is not only to group diseases with the same biological characteristics, but also to get insight into the pathogenesis and to define subgroups with different prognoses and different therapeutic approaches. In acute leukaemias the classification now most widely used is the French-American-British (FAB) classification as proposed in 1976, which was based on morphology and cytochemistry [1]. The FAB group felt that discrimination of myeloblasts from lymphoblasts on morphological characteristics only was insufficient. For this reason they proposed to define the difference between acute myeloid leukaemia (AML) and acute lymphoblastic leukaemia (ALL) by the positivity or negativity respectively of the blasts for the myeloperoxidase (MPO) or Sudan B Black reaction. Within acute myeloid leukaemia 6 categories were discriminated (M1-M6) by morphology and the use of $\alpha$-naphthyl acetate esterase (ANAE) to discriminate monoblasts from myeloblasts $[1,2]$.

Later, immunological markers were used to define

\footnotetext{
* Corresponding author. Department of Haematology, Dr. Daniel den Hoed Cancer Centre, P.O. Box 5201, 3008 AE Rotterdam, Netherlands. Fax: $(+31-10) 4842008$.
}

two new subtypes in acute myeloid leukaemia, the acute leukaemia with minimal myeloid differentiation (AML-M0) and the megakaryoblastic leukaemia (AML-M7), both being Sudan B Black negative but not lymphoblastic (Table 1) [3-5]. Immunological marker analysis, however, was not introduced into the FAB classification for ALL, even when the subdivision of the acute lymphoblastic leukaemias into L1 and L2, merely based on the size of the blasts, showed very little relevance to their biological features and prognosis $[1,7]$. Immunological marker analysis is pivotal in the classification of ALL. In this way not only the distinction between $\mathrm{T}$ and $\mathrm{B}$ lineage ALL can be made, but also distinct subgroups within these categories can be defined which are of biological and prognostic relevance $[8,9]$. The definition of $\mathrm{L} 3$, morphologically distinct from $\mathrm{L} 1$ and L2, and also with a typical immunological phenotype is overruled by the presence of a translocation of the MYC oncogene located on the long arm of chromosome 8 to either the immunoglobulin heavy-chain gene on chromosome $14(t(8 ; 14))$ or to one of the light-chain genes on chromosome 2 or 22 $(t(2 ; 8)$ or $t(8 ; 22))$ in nearly $100 \%$ of cases $[10-12]$.

The question then arises with respect to AML which on morphological and cytochemical grounds is much more differentiated than ALL, what im- 
Table 1

Summary of the FAB classification of AML

\begin{tabular}{ll}
\hline FAB subtype & Definition \\
\hline M0 & $<3 \% \mathrm{SBB}+{ }^{*}$ blasts, $\mathrm{My}+{ }^{* *}, \mathrm{Ly}-{ }^{* * *}$ \\
M1 & $>90 \%$ blasts \\
M2 & $30-90 \%$ blasts \\
& $>10 \%$ myeloid cells \\
& $<20 \%$ monocytoid cells \\
& majority promyelocytes \\
M3 & hypergranular \\
& microgranular \\
M3V & $>20 \%$ mature myeloid cells and \\
M4 & $>20 \%$ ANAE $+{ }^{* *}{ }^{*}$ blasts \\
& $>5 \times 10^{9} / 1$ monocytes in the blood \\
& $>80 \%$ monocytoid cells \\
M5 & $>50 \%$ nucleated erythroid cells \\
M6 & $>30 \%$ blasts of myeloid cells of the \\
& non erythroid population \\
M7 & $<3 \%$ SBB + blasts \\
& $>30 \%$ megakaryoblasts defined by CD41/CD61 \\
& or electron microscopy with platelet peroxidase \\
\hline
\end{tabular}

* Sudan Black B.

** Myeloid markers positive (CD13, CD33, myeloperoxidase, CDw65).

*** Lymphoid markers negative (CD3, CD5, CD10, CD19).

${ }^{* * * *} \alpha$-Naphthyl acetate esterase.

munological markers and cytogenetic analysis may contribute to the characteristics of the different subtypes.

\section{Concordance}

Essential to any classification is an acceptable level of reproducibility between observers. In the FAB classification the introduction of cytochemistry contributed to concordance compared to morphology alone, as did the definition of quantitative criteria for acute leukaemias, for instance, to distinguish acute myeloid leukaemias from the myelodysplastic syndromes $[1,2,13]$. But even then the reproducibility between observers varies from 45.7 to $86.8 \%$ [1418]. Review of AML bone marrow smears by the Dutch Slide Review Committee of Adult Leukaemias gives about $80 \%$ agreement. Most problems arise in discrimination between $\mathrm{M} 1$ and $\mathrm{M} 2$ and between M2 and M4 [19]. The addition of immunophenotyping to morphology and cytochemistry improves agreement between independent observers, although the estima- tion of Browman et al. who described an improvement to $99 \%$ seems fairly optimistic [14].

\section{Correlation between FAB subtypes and im munological phenotype}

Immunophenotyping can be helpful in confirming the diagnosis of AML and is indispensable in differentiating AML-M0 and AML-M7 from ALL (Table 1) [3-6]. For discrimination between myeloid leukaemias (M1-M3) and monocytic leukaemias (M4, M5) CD14 shows some correlation with monocytic leukaemias but is not very sensitive, being negative in the early monoblastic leukaemias [20,21]. Because distinct myeloid differentiation antigens are lacking, no further discrimination can be made immunologically between $\mathrm{M} 1$ and $\mathrm{M} 2$ than by the quantitative criteria of the FAB classification [19]. AML-M3, morphologically divided into two subtypes (hypergranular and hypogranular), both strongly positive for the myeloperoxidase reaction, shows a typical immunological pattern $(\mathrm{CD} 13+, \mathrm{CD} 33+, \mathrm{CD} 9+$, CD68 +, CD34 - , HLA-DR - , CD15 - ), but this pattern gives little additional information to a classification as the morphology itself is very characteristic and cytogenetic analysis is definite [22,23].

\section{Correlation between FAB subtypes and kary- otype}

Some chromosomal abnormalities are correlated to certain AML FAB subtypes and are of prognostic importance (Table 2). No specific chromosomal pattern was found in AML-M0 in different recent stud-

Table 2

\begin{tabular}{lll}
\hline Chromosomal translocations & $\begin{array}{l}\text { FAB } \\
\text { classification }\end{array}$ & $\begin{array}{l}\text { Relative } \\
\text { prognosis }\end{array}$ \\
\hline $\mathrm{t}(8 ; 21)(\mathrm{q} 22 ; \mathrm{q} 22)$ & M2 & fair to good \\
$\mathrm{t}(15 ; 17)(\mathrm{q} 22 ; \mathrm{q} 21)$ & M3 & $\begin{array}{l}\text { fair to good } \\
\text { good }\end{array}$ \\
$\operatorname{inv}(16)(\mathrm{p} 13 ; \mathrm{q} 22) / \mathrm{t}(16 ; 16)$ & M4eo & \\
$(\mathrm{p} 13 ; \mathrm{q} 22)$ & & poor \\
$\mathrm{t}(9 ; 1)(\mathrm{p} 21 ; \mathrm{q} 23)$ & M5 & poor \\
$\mathrm{t}(11 \mathrm{q} 23)$ & M4-M5 & poor \\
$\mathrm{t}(6 ; 9)(\mathrm{p} 23 ; \mathrm{q} 34)$ & M2, M4 & undetermined \\
$\mathrm{t}(8 ; 16)(\mathrm{p} 11 ; \mathrm{p} 13)$ & M5 & undetermined \\
inv(3)(q21;q26)/t(3;33) & M4 & \\
$\mathrm{t}(1 ; 3)(\mathrm{p} 36 ; \mathrm{q} 21)$ & & undetermined \\
$\mathrm{t}(1 ; 22)(\mathrm{p} 13 ; \mathrm{q} 13)$ & $\mathrm{M} 7$ & \\
\hline
\end{tabular}


ies [24-27]. In contrast, a higher frequency of abnormal karyotypes, complex karyotypes and unbalanced chromosomal changes $(-5 / 5 q-$ and $/$ or $-7 / 7 q-$ and +13) compared with AML-M1 were observed by Cunea et al. in a large study of 26 patients, which may partly account for the very poor outcome in these patients [28]. Ninety percent of the patients whose leukaemia shows $t(8 ; 21)(\mathrm{q} 22 ; \mathrm{q} 22)$ have AML-M2. This subtype has a better prognosis than other subtypes [29]. In contrast, many leukaemias categorized as M2 have other or no cytogenetic abnormalities and may be derived from transformed myelodysplastic syndromes or early diagnosed AML-M1 having less than $30 \%$ blasts but with a maturing granulocytic component like AML-M2. As stated, virtually all promyelocytic leukaemias (M3) have $\mathbf{t}(15 ; 17)(\mathrm{q} 22 ; \mathrm{q} 21)$. Hence one should reconsider the M3 classification if $t(15 ; 17)$ cannot be demonstrated. This subtype, clinically characterized by its bleeding tendency, needs special treatment with retinoid acid and has a better prognosis than the other subtypes [30]. The good prognostic $\operatorname{inv}(16)(\mathrm{p} 13 \mathrm{q} 22)$ is associated with the diagnosis of M4 EO [31]. Common translocations such as $\mathrm{t}(6 ; 11)(\mathrm{q} 26 \mathrm{q} 23), \mathrm{t}(9 ; 11)(\mathrm{p} 21 ; \mathrm{q} 23)$ and $\mathrm{t}(11 ; 19)$ (q23;p13) are found in monocytic leukaemias [29]. In acute myeloid leukaemia originating from myelodysplastic syndrome $-5 / 5 q-$ or $-7 / 7 q-$ is frequently found, and has a poor prognosis [32]. Complex karyotypic abnormalities are also associated with a poor prognosis [31]. Thus, to define the prognosis of certain AML subtypes, cytogenetic analysis is indispensable.

\section{Differentiation between MDS and AML}

The discrimination between AML and refractory anaemia with excess of blasts in transformation (RAEB-t) is based on the limit of $30 \%$ of nucleated bone marrow cells being blasts for the latter $[1,2,13]$. This $30 \%$ limit is arbitrary and with this limit not all cases of acute leukaemias will be recognized. For example, patients with de novo AMI, with a rapidly rising blast count but less than $30 \%$ blasts will not be regarded as having acute myeloid leukaemia. Immunophenotyping makes no contribution in distinguishing between AML and MDS, but cytogenetical analysis will add important information. In de novo AML translocations are often found; in the myelodysplastic syndromes, on the other hand, numeric chromosomal abnormalities such as $-5 / 5 q-$, $-7 / 7 q-$ or +8 are more frequently observed [3234].

\section{Sudan B Black negative acute leukaemias}

Following the FAB classification, Sudan B Black negative acute leukaemias are of myeloid (M0), megakaryocytic (M7) or lymphoblastic origin (ALL) [3-5]. However, there are some other Sudan B Black

Table 3

Definition of subtypes in Sudan B Black negative leukaemias

\begin{tabular}{|c|c|c|}
\hline Subtypes & Immunophenotype & \\
\hline ALL & $\mathrm{Ly}+* * *$ & \\
\hline AML M7 & CD41 and/or CD42 and/or CD61 & \\
\hline AML M0 & $\mathrm{My}+* * * *, \mathrm{Ly}-* * * * *$ & $\mathrm{CD} 34+, \mathrm{HLA}-\mathrm{DR}+$ \\
\hline AEL & no lineage markers available & $(\mathrm{CD} 34+$, HLA-DR +$)$ \\
\hline AUL $* *$ & My $-* * * * * *$, Ly - & $(\mathrm{CD} 34+$, HLA-DR +$)$ \\
\hline SBB negative biphenotypic AL & $\mathrm{My}+, \mathrm{Ly}+$ & $($ CD34,+ HLA-DR +$)$ \\
\hline
\end{tabular}

\footnotetext{
" $\mathrm{AEL}=$ hypothetical acute erythroblastic leukaemia (less differentiated than AML-M6).

* AUL $=$ acute undifferentiated leukaemia.

$* * *$ Lymphoid markers positive (CD3, CD22, CD79a).

$* * * *$ Myeloid markers positive (CD13, CD33, myeloperoxidase, CDw65, CD117).

$* * * * *$ Lymphoid markers negative

****** Myeloid markers negative.
} 
negative acute leukaemias not described in the FAB classification such as acute undifferentiated leukaemia (AUL) and acute erythroblastic leukaemia (Table 3). Without immunophenotyping the classification of acute undifferentiated leukaemia is impossible $[35,36]$. For the hypothetical early erythroblastic leukaemias no early erythroid markers are available so far. Most often the undifferentiated or minimally differentiatied leukaemias are CD34 + [24$26,35,36]$. It is not known if cytogenetical analysis adds more information in these subtypes.

\section{Biphenotypic and bilineage acute leukaemias}

In the FAB classification there is a strict discrimination between acute myeloid leukaemia and acute lymphoblastic leukaemia. However, a small subset of leukaemias (less than 5\%) consist of leukaemic cells expressing markers of both myeloid and lymphoid lineage (biphenotypic leukaemias) or consist of two different populations of cells each expressing different markers (bilineage acute leukaemias) [3,38]. Markers expressed on more than $20 \%$ of the blasts are considered positive, except for TdT (more than $10 \%$ expression). Here, the FAB classification is lacking and immunophenotyping is essential for the recognition of these types of leukaemias. Catovsky et al. proposed a scoring system to distinguish biphenotyping acute leukaemias from acute leukaemias with aberrant expression, using immunophenotyping and rearrangement of the B or T-cell receptor $[3,37]$. This scoring system has recently been updated by the European Group for Immunophenotyping of Leukaemias (EGIL) [38]. Prognosis and choice of treatment are difficult to determine since larger studies are never published, but the prognosis seems very poor.

\section{Prognostic value of the FAB classification}

In AML, some differences in prognosis are seen between the different AML FAB subtypes. AML-M0 has a worse outcome than all other subtypes of AML [24,26-28]. M1 shows a lower remission rate than M2 and M4. M3 has a much better prognosis than the other subtypes. M5, M6 and M7 show a lower remission rate $[19,39]$. Immunophenotyping is of no prognostic value. Studies on the prognostic value of CD34 expression are inconclusive, as is CD7 expression [40-43]. The prognosis for the different FAB subtypes is best correlated with characteristic cytogenetic abnormalities-e.g., $t(15 ; 17), t(8 ; 21)$, inv(16) or del(16) (Table 2) [29-31].

\section{Conclusions}

The FAB classification is a good guide to classifying AML, on the basis of morphologically recognizable criteria, but is insufficient for the recognition of undifferentiated leukaemias, Sudan B Black negative non-lymphoblastic leukaemias, biphenotypic and bilineage leukaemias, and certain important subgroups like $\mathrm{t}(8 ; 21)$ in AML-M2. Immunophenotyping and cytogenetics are therefore indispensable. An attempt to integrate morphological, immunological and cytogenetic methods into a new classification was made by the MIC Cooperative Study Group (Table 4), but so far only 10 categories have been defined, which means that not all acute myeloid leukaemias can be categorised in this classification [44].

In addition, several new techniques can make important contributions to the diagnosis and monitoring of acute leukaemias. Fluorescent in situ hybridization (FISH) can be routinely used to identify specific chromosomes involved in chromosome

Table 4

The MIC classification of AML

\begin{tabular}{lll}
\hline Karyotypic change & Morphology (FAB) & $\begin{array}{l}\text { Suggested MIC } \\
\text { nomenclature }\end{array}$ \\
\hline $\mathrm{t}(8 ; 21)(\mathrm{q} 22 ; \mathrm{q} 22)$ & $\mathrm{M} 2$ & $\mathrm{M} 2 / \mathrm{t}(8 ; 21)$ \\
$\mathrm{t}(15 ; 17)(\mathrm{q} 22 ; \mathrm{q} 12)$ & $\mathrm{M} 3, \mathrm{M} 3 \mathrm{v}$ & $\mathrm{M} 3 / \mathrm{t}(15 ; 17)$ \\
$\mathrm{t} /$ del $/(11)(\mathrm{q} 23)$ & M5a(M5b, M4) & $\mathrm{M} 5 \mathrm{a} / \mathrm{t}(11 \mathrm{q})$ \\
inv/del(16)(q22) & M4Eo & $\mathrm{M} 4 \mathrm{E} \mathrm{inv}(16)$ \\
$\mathrm{t}(9 ; 22)(\mathrm{q} 34 ; \mathrm{q} 11)$ & $\mathrm{M} 1(\mathrm{M} 2)$ & $\mathrm{M} 1 / \mathrm{t}(9 ; 22)$ \\
$\mathrm{t}(6 ; 9)(\mathrm{p} 21-22 ; \mathrm{q} 34)$ & M2 or M4 with & $\mathrm{M} 2 / \mathrm{t}(6 ; 9)$ \\
& basophilia & \\
inv(3)(q21q26) & M1(M2, M4, M7) with & $\mathrm{M} 1 /$ inv(3) \\
& thrombocytosis & \\
$\mathrm{t}(8 ; 16)(\mathrm{p} 11 ; \mathrm{p} 13)$ & M5b with phagocytosis & $\mathrm{M} 5 \mathrm{~b} / \mathrm{t}(8 ; 16)$ \\
$\mathrm{t} /$ del(12)(p11-13) & M2 with basophilia & $\mathrm{M} 2 \mathrm{Baso} / \mathrm{t}(12 \mathrm{p})$ \\
+4 & M4(M2) & $\mathrm{M} 4 /+4$ \\
\hline
\end{tabular}


translocations $[45,46]$. More cells can be observed than with cytogenetic analysis and it is not restricted to cells in metaphasis. Direct correlation of chromosomal abnormalities with morphology or immunological markers is possible by this technique $[47,48]$. The polymerase chain reaction (PCR) is used as a fast and reliable technique to detect chromosomal re-arrangements, e.g., $t(8 ; 21)$ and $t(15 ; 17)$, at diagnosis and can be used for the detection of minimal residual disease after treatment due to its high sensitivity [49-51].

Expression of P-glycoprotein, a protein associated with multidrug resistance and treatment failure, may be of prognostic significance $[52,53]$.

Thus, the FAB classification is not outdated for the diagnosis of AML, but it does require other procedures for refinement of the diagnosis and determination of the prognosis. This classification remains an important cornerstone of a "combined modality' classification of the acute myeloid leukaemias.

\section{References}

[1] Bennett JM, Catovsky D, Daniel M-T, et al. Proposals for the classification of the acute leukaemias. $\mathrm{Br} \mathrm{J}$ Haematol 1976:33:451-458.

[2] Bennett JM, Catovsky D, Daniel M-T, et al. Proposed revised criteria for the classification of acute myeloid leukemia. Ann Intern Med 1985;103:620-625.

[3] Catovsky D, Matutes E, Buccheri V, et al. A classification of acute leukaemia for the 1990s. Ann Hematol 1991;62:16-21.

[4] Bennett JM, Catovsky D, Daniel M-T, et al. Proposal for the recognition of minimally differentiated acute myeloid leukacmia (AML-M0). Br J Haematol 1991;78:325 329.

[5] Bennett JM, Catovsky D, Daniel M-T, et al. Criteria for the diagnosis of acute leukemia of megakaryocyte lineage (M7). Ann Intern Med 1985;103:460-462.

[6] Knapp W, Dörken B, Rieber P, Schmidt RE, Stem H, von dem Borne AEG Kr. CD antigens 1989. Blood 1989;74:1448-1450.

[7] Bennett JM, Catovsky MT, et al. The French-AmericanBritish (FAB) Cooperative Group 1981. The morphological classification of acute lymphoblastic leukaemia: concordance among observers and clinical correlations. $\mathrm{Br} \mathbf{J}$ Haematol $1981 ; 47: 553-561$.

[8] First MIC Cooperative Study Group. Morphologic, immunologic and cytogenetic (MIC) working classification of acute lymphoblastic leukaemias. Cancer Genet Cytogenet 1986;23:189-197.
[9] Hayhoe FGJ. Classification of acute leukaemias. Blood Rev 1988:2:186-193

[10] Lai JL. Fenaux P, Zandecki M. Nelken B, Huart JJ, Deminatti $M$. Cytogenetic studies in 30 patients with Burkitt's lymphoma or L3 acute lymphoblastic leukaemia with special reference to additional chromosome abnormalities. Ann Genet 1989;32:26-31.

[11] Third International Workshop on Chromosomes in Leukemia. Chromosomal abnormalities and their clinical significance in acute lymphoblastic leukemia. Cancer Res 1983;43:868-873.

[12] Secker-Walker LM. The prognostic implications of chromosomal findings in acute lymphoblastic leukemia. Cancer Genet Cylogenet 1984:11:233-241

[13] Bennett IM. Catovsky D. Daniel M-T. et al. Proposals for the classification of the myelodysplastic syndromes. Br J Haematol 1982;189-199.

[14] Browman GP, Neame PB, Soamboonsrup P. The contribution of cytochemistry and immunophenotyping to the reproducibility of the FAB classification in acute leukemia. Blood 1986:68:900-905.

[15] Head DR. Savage RA, Cerezo I, et al. Reproducibility of the French-American-British classification of acute leukemia: The Southwest Oncology Group experience. Am J Hematol 1985:18:45-57.

[16] Drexler HG. Classification of acute myeloid leukemias. A comparison of $\mathrm{FAB}$ and immunophenotyping. Leukemia 1987;1:697-705.

[17] Whittacker JA, Withey J, Powell DEB, Parry TE, Khurshid M. Leukemia classification: a study of the accuracy of diagnosis in 456 patients. Br J Haematol 1979;41:177-184.

[18] Dick FF, Armitage JO, Burns CP. Diagnostic concurrence in the subclassification of adult acute leukemia using FrenchAmerican-British criteria. Cancer 1982;49:916-920.

[19] Bain B.I. Teukemia diagnosis. A guide to the FAB classification. London: Wolfe Publishing. 1993.

[20] Linch DC, Allen C. Beverly PCL, Bynoe AG, Scott CS, Hogg $N$. Monocional antibodies differentiating between monocytic and myelomonocytic variants of AML. Blood 1983;63:566-573.

[21] San Miguel JF, Gonzalez M, Canizo MC, Anta JP, Zola H, Lopez Borrasca A. Surface marker analysis in acute myeloid lcukacmia and correlation with the F$\wedge \mathbf{B}$ classification. Br J Haematol 1986:64:547-560

[22] Erber WN, Asbahr H, Rule SA, Scott CS. Unique immunophenotype of acute promyelocytic leukemia as defined by CD9 and CD68 antibodies. Br J Haematol 1994:88:101104

[23] Larson RA, Kondo K, Vardiman JW. Evidence for a 15;17 translocation in every patient with acute promyelocytic leukemia. Am J Med 1984;76:827-841.

[24] Segeren CM, de Jong-Gerrits GCMM, van 't Veer MB. AML-M0: clinical entity or waste basket for immature blasric leukaemias? A description of 14 patients. Ann Haematol 1995:70:297--300.

[25] Lee EJ, Pollak A, Leavitt RD, Testa JR, Schiffer CA. Minimally differentiated acute nonlymphocytic leukemia: a distinct entity. Blood 1987;70:1400-1406. 
[26] Venditti A, Del Poeta G, Stasi R, et al. Minimally differentiated acute myeloid leukaemia (AML-M0): cytochemical, immunophenotypic and cytogenetic analysis of 19 cases. $\mathrm{Br} \mathrm{J}$ Haematol 1994;88:784-793.

[27] Sempere A, Jarque L, Guinot M, et al. Acute myeloblastic leukemia with minimal myeloid differentiation (FAB AMLM0): a study of eleven cases. Leukemia Lymphoma 1993;12:103-108.

[28] Cuneo A, Ferrant A, Michaux JL, et al. Cytogenetic profile of minimally differentiated (FAB M0) acute myeloid leukemia:correlation with clinicobiologic findings. Blood 1995;85:3688-3694.

[29] Fourth International Workshop on Chromosomes in Leukemia, 1982. Overview of association between chromosomal pattern and cell morphology, age, sex and race. Cancer Genet Cytogenet 1984;11:265-283.

[30] Grignani F, Fagiolo M, Alcalay M. Acute promyelocytic leukemia: from genetics to treatment. Blood 1994;83:10-25.

[31] Larson RA, Williams SF, Le Beau MM, et al. Acute myelomonocytic leukemia with abnormal eosinophils and inv(16) or $t(16 ; 16)$ has a favourable prognosis. Blood 1986;68:1242-1249.

[32] Walker H, Smith FJ, Betts DR. Cytogenetics in acute myeloid leukaemia. Blood Rev 1994;8:30-36.

[33] Third MIC Cooperative Study Group. Recommendations for a morphologic, immunologic and cytogenetic (MIC) working classification of primary and therapy-related myelodysplastic disorders. Cancer Genet Cytogenet 1988;32:1-10.

[34] Yunis JJ, Lobell M, Arnesen MA, et al. Refined chromosomal study helps define prognostic subgroups in most patients with primary myelodysplastic syndrome and acute myeloid leukemia. Br J Haematol 1988;68:189-194.

[35] Campara D, Hansen-Hagge TE, Matutes E, et al. Phenotypic, genotypic, cytochemical and ultrastructural characterization of acute undifferentiated leukemia. Leukemia 1990;4:620624.

[36] LeMaistre A, Childs A, Hirsh-Ginsberg C, et al. Heterogeneity in acute undifferentiated leukemia. Hematol Pathol 1988;2:79-89.

[37] Matutes E, Catovsky D. The value of scoring systems for the diagnosis of biphenotypic leukemia and mature B-cell disorders. Leukemia Lymphoma 1994;13:11-14.

[38] European Group for the Immunological Characterization of Leukemias (EGIL): Bene MC, Castoldi G, Knapp W et al. Proposals for the immunological classification of acute leukemias. Leukemia 1995;9:1783-1786.

[39] Schiffer CA, Lee EJ, Tomiyasu T, Wiernik PH, Testa JR. Prognostic impact of cytogenetic abnormalities in patients with the de novo acute nonlymphocytic leukemia. Blood 1989;73:263-270.

[40] Tucker J, Dorey E, Gregory WY. Immunophenotype of blast cells in acute myeloid leukemia may be useful predictor for outcome. Hematol Oncol 1990;8:47-58.
[41] Campos L, Guyotat D, Archimbaud E. Surface marker expression in adult acute myeloid leukaemia: correlation with initial characteristics, morphology and response to therapy. Br J Haematol 1989;72:161-166.

[42] Del Poeta G, Stasi R, Venditti A, et al. Prognostic value of cell marker analysis in de novo acute myeloid leukemia. Leukemia 1994;8:388-394.

[43] Lo Coco F, De Rossi G, Pasqualetti D. CD7 positive acute myeloid leukemia: a subtype associated with cell immaturity. Br J Haematol 1989;73:480-485.

[44] Second MIC Cooperative Study Group. Morphologic, immunologic and cytogenetic (MIC) working classification of the acute myeloid leukemias. Br J Haematol 1988;68:487494.

[45] Gray JW, Kuo WL, Liang J, et al. Analytical approaches to detection and characterization of disease-linked chromosome aberrations. Bone Marrow Transplant 1990;6:14-19.

[46] Nylund SJ, Ruutu T, Saarinen U, Larramendy ML, Knuutila S. Detection of minimal residual disease using fluorescence DNA in situ hybridization:a follow-up in leukemic and lymphoma patients. Leukemia 1994;8:587-596.

[47] Anastasi J, Vardiman JW, Rudinsky R, et al. Direct correlation of cytogenetic findings with cell morphology using in situ hybridization and analysis of suspicious cells in bone marrow specimens of two patients completing therapy for acute lymphoblastic leukemia. Blood 1991;77:2456-2462.

[48] Weber-Mathiesen K, Winkemann M, Muller-Hemerink A, Schlegelberger B, Grote W. Simultaneous fluorescence immunophenotyping and interphase cytogenetics: a correlation to characterization of tumor cells. $\mathrm{J}$ Histochem Cytochem 1992:40:171-175.

[49] Lo Coco F, Diverio D, Pandolfi PP, et al. Molecular evaluation of residual disease as predictor of relapse in acute promyelocytic leukaemia. Lancet 1992;340:1437-1438.

[50] Miller Jr WH, Kakizuka A, Frankel SR, et al. Reverse transcription polymerase chain reaction for the rearranged retinoic acid receptor $\alpha$ clarifies diagnosis and detects minimal residual disease in acute promyelocytic leukemia. Proc Natl Acad Sci USA 1992;89:2694-2698.

[51] Nisson PE, Watkins PC, Sacchi N. Transcriptionally active chimeric gene derived from the fusion of the AML1 gene and a novel gene as chromosome 8 in $t(8 ; 21)$ leukemic cells. Cancer Genet Cytogenet 1992;63:81-88.

[52] Campos L, Guyotat D, Archimbaud E, et al. Clinical significance of multidrug resistance P-glycoprotein expression on acute nonlympho-blastic leukemia cells at diagnosis. Blood 1992;79:473-476.

[53] Zöchbauer S, Gsur A, Brunner R, Kyrle PA, Lechner K, Pirker R. P-glycoprotein expression as unfavorable prognostic factor in acute myeloid leukemia. Leukemia 1994;8:974977. 